\title{
ARTIGO
}

\section{O HUMOR DO SAPATEIRO DA PEÇA JÚLIO CÉSAR EM TRADUÇÃO ANOTADA E COMENTADA}

\author{
Tiago Marques Luiz \\ Universidade Estadual de Mato Grosso do Sul (UEMS), Brasil \\ markx2006@gmail.com \\ Lucilia Teodora Villela de Leitgeb Lourenço \\ Universidade Estadual de Mato Grosso do Sul (UEMS), Brasil \\ lucilia@uems.br
}

DOI: https://doi.org/10.26512/caleidoscopio.v4i2.29617

Recebido em: $14 / 02 / 2020$
Aceito em: 01/10/2020
Publicado em maio de 2021

Resumo: Esta tradução anotada e comentada da peça trágica Júlio César, embasada na articulação entre os Estudos da Tradução e os Estudos Shakespearianos, tem como propósito oferecer ao estudante de Letras e de Teatro um texto que possa simultaneamente funcionar como um roteiro como também ser legível e encenável, dada a dupla natureza da tradução dos textos shakespearianos, que ora são destinados à página, ora ao palco. Antes de se dar início à tradução propriamente dita, é necessário tecer considerações pertinentes acerca da tradução teatral do texto shakespeariano, mais precisamente da figura do clown, um personagem correspondente ao bobo da corte na época shakespeariana. Após o embasamento teórico proveniente das considerações de Bárbara Heliodora, Delia Chiaro, Dirk Delabastita, Susan Bassnett, entre outros nomes oriundos dos Estudos da Tradução e dos Estudos Shakespearianos, apresentamos nossa tradução com comentários e notas. A cena traduzida é a de abertura da peça, na qual somos apresentados ao Sapateiro, um cidadão proveniente da classe trabalhadora que, valendo-se de ambiguidades e jogos de palavras referentes ao seu ofício, ridiculariza os tribunos Flávio e Marulo.

Palavras-chave: Tradução anotada e comentada. Júlio César. Humor. Shakespeare.

\section{THE COBBLER'S HUMOR OF JULIUS CAESAR PLAY IN ANNOTATED AND COMMENTED TRANSLATION}

\begin{abstract}
This annotated and commented translation of the tragic play Julius Caesar, based on the articulation between Translation Studies and Shakespearean Studies, aims to offer the student of Literature and Theater a text that is both able to function as a script as well as be legible and playable, given the double nature of the translation of Shakespearean texts, which are sometimes destined for the page, sometimes for the stage. Before starting the translation, itself, it is necessary to make pertinent considerations with regard to the theatrical translation of the Shakespearean text, more precisely the figure of the clown, a character corresponding to the jester in Shakespearean times. After the
\end{abstract}


theoretical basis from the considerations of Bárbara Heliodora, Delia Chiaro, Dirk Delabastita, Susan Bassnett, among other names from Translation Studies and Shakespearean Studies, we present our translation with comments and notes. The translated scene is the opening of the play, in which we are introduced to Cobbler, a citizen from the working class who, using ambiguities and word games related to his profession, ridicules the tribunes Flavius and Marullus.

Keywords: Annotated and commented translation. Julius Caesar. Humor. Shakespeare.

\section{Considerações iniciais}

William Shakespeare tem sido traduzido e adaptado para o espaço das telas do cinema, da televisão, como também para as histórias em quadrinhos e no próprio espaço do palco, seja em uma encenação ou dança. A genialidade do bardo não conheceu o limite cronológico que o separa de nossa contemporaneidade, como também o fenômeno do humor, que desde a concepção proveniente da Antiguidade Clássica, vem sendo ressignificado com o deslindar da História, como propõe a tripartite feita por Minois (2003): o riso divino, o riso diabólico e o riso social.

Em relação à dicotomia de uma tradução destinada à página ou ao palco do texto shakespeariano, é necessário que o tradutor tenha um projeto para com esse texto; se será transformado em livro ou em uma encenação no palco, e que esses sistemas semióticos possuem sua própria linguagem e estrutura para com o texto que será formatado. No tocante ao livro, temos as páginas, paratextos, ilustrações, o tipo de fonte a ser usada na escrita, capa e dimensão da fisicalidade do livro, ao passo que o palco demanda uma interação instantânea entre os atores e com a plateia, quando necessário.

O trabalho com o livro e com o palco demandam conhecimentos técnicos acerca desses códigos semióticos e que o tradutor não pode prescindir, tais como: no caso do livro, o aumento ou a diminuição da fonte, uso de balões [se pensarmos em Histórias em Quadrinhos], cores, layout, textura do papel, caracterização dos personagens pelo artista visual do livro. Em relação ao teatro, a linguagem não verbal potencializa as palavras escritas por meio do cenário, do figurino, indumentária, sonoplastia, maquiagem, jogo de luz e o próprio espaço do palco, no qual os atores estarão transitando, e no tocante ao elemento verbal, a oralidade é muito relevante, pois cabe ao ator/atriz soar convincente quando no momento da representação. A proposição que aqui fazemos nessa articulação entre palavra e voz, é que para a Literatura, a palavra escrita tem maior relevância, ao passo que na esfera cênica, a voz é o fio condutor do espetáculo. 
Quando se trata do elemento do humor, como ele se materializa no livro e no palco? Sabe-se que o humor, enquanto conceito elástico, pode significar jogo de palavras, ironia, derrisão, sátira, mecanicismo, entre outros conceitos referentes à graceza, mas quando se trata de se materializar em um suporte, existem todo um trabalho para acentuar esse elemento na narrativa, por meio de onomatopeias, ou ilustrações que denotem o caráter engraçado, como um possível escorregão, um grupo de amigos rindo de uma situação pela qual vivenciaram, etc. No livro, esses exemplos podem ser descritos por um personagem, pelo próprio narrador ou serem ilustrados por meio de balões ou as onomatopeias, cujas fontes podem redimensionar o caráter cômico daquela passagem, ao passo que no teatro, o humor pode ser desencadeado pela própria interação entre os atores, por meio de um tapa, um se esbarrar no outro e irem ao chão, um mal-entendido, uma piada, etc, deixando a criatividade a cargo dos agentes do espetáculo, por meio de ensaios consecutivos até a cena chegar a plateia.

Em relação a Shakespeare, as passagens cômicas podem atender quatro premissas propostas por Arthur Nason (1906): a) serem realmente cômicas; b) serem contrastantes com a narrativa séria, gerando o nonsense ou o ridículo; c) aliviarem a tensão de toda a tragédia que se sucedeu e preparar o espectador para o clímax; e d) aumentarem ainda mais a tensão da cena, contudo, Nason (1906) postula que o leitor contemporâneo, dependendo de seu temperamento, pode atribuir mais de uma classificação a determinada passagem, assim como não significa que cada passagem é de classificação estanque.

No que diz respeito à tradução desse fenômeno complexo, o tradutor (literário e/ou teatral) não pode prescindir de criatividade, bagagem cultural de ambas as línguas, como também da competência comunicativa para que o texto-traduzido retome o propósito de gerar o riso no leitor ou espectador. A partir de Nason, elencamos uma cena a ser traduzida da peça trágica Júlio César, de William Shakespeare. A cena do Sapateiro (Ato I, Cena I) corresponde à primeira classificação de Nason - uma cena totalmente cômica - pois se trata do Sapateiro, um personagem conhecido como clown, cujo repertório humorístico provém das ambiguidades e jogos de palavras referentes ao seu ofício.

Ao cotejarmos traduções a que tivemos acesso, assim como leitura de edições anotadas da referida peça, propomos uma tradução anotada e comentada dessa cena; 
embora esse tipo de tradução esteja vinculado à tradução literária, queremos frisar que nossas notas e comentários podem servir de norteamento para os agentes do teatro que queiram viabilizar uma encenação.

A tradução ora proposta visa resgatar a comicidade de uma personagem secundária. Na cena que abre o primeiro ato, vemos uma aglomeração de pessoas nas ruas de Roma, com os cidadãos comemorando a vitória de César, que retornava de uma batalha contra os filhos de Pompeu. 0 tópico norteador dessa proposta de tradução é a tradução do humor que, segundo pesquisadores como Anne Leibold (1989), Salvatore Attardo (2002), Dirk Delabastita $(1996,2002)$, entre outros, apresenta certo grau de dificuldade, pois exige do tradutor imaginação e criatividade para brincar com o sentido das palavras, não apenas limitando-se ao campo semântico, mas também ao teor cultural dessas palavras, com desafios que incluem trocadilhos, ironias, jogos de palavras, etc.

Embora o eixo norteador seja a tradução do humor, primeiramente é necessário tecer algumas considerações acerca da tradução em geral, para depois, adentrarmos à tradução literária e teatral, e finalizarmos ao campo da tradução do humor no teatro.

\section{A tríade tradução, humor e Shakespeare}

A partir da famosa teorização de Roman Jakobson (2000) que divide a tradução em intralingual, interlingual e intersemiótica, nos valeremos da tradução interlingual, uma vez que "consiste na interpretação dos signos verbais por meio de alguma outra língua" (JAKOBSON, 2001, p. 64), o que significa que o texto-traduzido há de representar o conteúdo do texto-fonte, e como bem enfatiza Jakobson (2000), não há "equivalência completa entre as unidades de código, ao passo que as mensagens podem servir como interpretações adequadas das unidades de código ou mensagens estrangeiras" (JAKOBSON, 2001, p. 64). Embora seja desejável que o texto traduzido saiba reproduzir o mesmo conteúdo do texto-fonte, tem-se ciência de que o tradutor, no momento de traduzir esse texto, irá trazer a sua bagagem de leitura e interpretação do conteúdo, o que significa que cada tradução de determinada obra é tão original quanto.

Corrobora-se com Jakobson a observação feita por Bassnett (2011) de que a tradução não está apenas limitada ao domínio das palavras; a teórica argumenta que o tradutor não apenas está trazendo as palavras ali registradas, "mas o contexto ausente em 
que essas palavras aparecem, o texto por trás do texto, por assim dizer, para evitar os perigos do literalismo e criar algo que vale a pena" (BASSNETT, 2011, p. xiii, tradução nossa $\left.{ }^{81}\right)$.

O humor é explorado por diferentes gêneros, sejam eles teatrais, como a comédia e a sátira, ou textuais, como a piada e a charge. Uma das modalidades mais sofisticadas de humor visa produzir efeito cômico a partir de jogos de palavras, como paronomásias, metáteses, anagramas, palíndromos, ironias, malapropismos, neologismos, alusões, polissemias, homofonias, homonímias, equivocidades, calemburs, palavras-valises e citações truncadas. Alguns escritores se especializaram nesses jogos de palavras, como William Shakespeare, por exemplo, que, em suas peças, soube explorar amiúde esse dispositivo linguístico para produzir um efeito de sentido na narrativa como também gerar a catarse do riso no seu espectador. Todos esses tipos de jogo de palavra podem ser considerados modalidades do que Delia Chiaro chama de "humor verbal" (CHIARO, 2010, p. 1, tradução nossa ${ }^{82}$ ). Entre todos esses tipos de jogos, o trocadilho ocupa um lugar de destaque nos dramas do bardo inglês.

A criatividade está atrelada à perspicácia e inteligência do ator/humorista em fazer o seu leitor/espectador rir. 0 tradutor/adaptador/humorista deve, segundo Amparo Hurtado Albir (2001), se basear em três etapas: a compreensão, a desverbalização e a reexpressão, isto é, apreender o sentido do texto original [compreensão], sair do campo lexical e reter o sentido no campo cognitivo [desverbalização] e, por fim, buscar expressar esse sentido primeiro numa língua-alvo, permitindo que o leitor-alvo tenha a mesma percepção que o leitor do texto-fonte [reexpressão] (HURTADO ALBIR, 2001).

Além dos três elementos supracitados, existem mais dois a serem levados em consideração: o gênero textual com suas devidas particularidades e o público que irá receber esse texto. No caso de Shakespeare, estamos falando do teatro e a sua relação com um público proveniente das variadas esferas sociais. Como bem sabemos, Shakespeare foi reconhecido por enfatizar a individualidade dos personagens de acordo com a cultura que se desenvolvia no ocidente de sua época, trazendo-os ao centro de suas ações e arcar com

\footnotetext{
${ }^{81}$ No original: "but the absent context in which those words appear, the text behind the text, as it were, if they are to avoid the perils of literalism and create something worthwhile".

82 No original: "verbal humor"
} 
as consequências de suas escolhas, o que é comprovado por meio de Hamlet, Macbeth, Romeu e Julieta, entre outros personagens marcantes de sua dramaturgia.

E traduzir Shakespeare em solo brasileiro não diz respeito apenas à reelaboração linguística de seus textos, mas também na reconstrução da sua arte cênica, a qual lhe rendeu grande prestígio; traduzir o humor dos personagens no palco é uma das modalidades mais sofisticadas de humor, que visa produzir efeito cômico a partir de jogos de palavras. Dependentes dos significados próprios a cada língua, esses jogos de palavras são frequentemente intraduzíveis.

Como bem advertido por Dirk Delabastita (2002), o tradutor que lida com essa linguagem presente no texto dramático acaba realizando uma tradução, amparado por uma pauta nacionalista, possivelmente política, assim como também elementos externos ao texto-fonte, como a própria língua, as convenções de gênero textual e do processo de tradução como um todo. Delabastita (2002) é categórico ao dizer que o grau de complexidade dessas forças externas "é tanto a ponto de pôr em dúvida a noção de uma teoria "geral" do humor e da (sua) tradução. Precisamos de um estudo empírico adicional de textos e contextos, envolvendo uma interpretação cautelosa de possíveis razões e possíveis efeitos" (DELABASTITA, 2002, p. 303, tradução nossa83), e não apenas da tradução das peças, mas enfaticamente no humor presente nelas, uma vez que os clowns, personagens provenientes das classes baixas mesclam não apenas o idioma inglês, mas outros códigos linguísticos como o francês e o latim, e que esse "sabor especial deve mais ao dialeto de classe do que ao regional, além de demonstrar afeição por palavras aprendidas e frases estrangeiras" (DELABASTITA, 2002, p. 305, tradução nossa ${ }^{84}$ ).

Para esse trabalho, citamos a definição simples e acertada de Patrick Zabalbeascoa (2001), que vê no humor um propósito comunicativo "de produzir o riso ou graça (no sentido de ser cômico) nos destinatários do texto (ZABALBEASCOA, 2001, p. 255, tradução nossa ${ }^{85}$ ). E no que diz respeito à traduzibilidade desse elemento, no tocante ao erro e suas limitações, vamos ao encontro de Jeroen Vandaele (2010), cujas palavras direcionam para a vertente cultural do humor:

\footnotetext{
${ }^{83}$ No original: "is such as to cast doubt on the notion of a 'general' theory of humour and (its) translation. We need further empirical study of texts and contexts, involving a cautious interpretation of possible reasons and possible effects"

${ }^{84}$ No original: "special flavor owes more to class dialect than to regional dialect, while also displaying a fondness for learned words and foreign phrases".

85 No original: "de producir una reacción de risa o sonrisa (de ser gracioso) en los destinatarios del texto".
} 
De um lado, qualquer falha tradutória será, pois, muito visível: é óbvio que o tradutor falhou quando não se ri do humor traduzido. Do outro, o tradutor de humor tem que lidar com o fato de que as "regras", as "expectativas", as "soluções" e os acordos de "jogo social" são muitas vezes específicos de grupos ou culturas (VANDAELE, 2010, p. 149, tradução nossa ${ }^{86}$ )

O humor suscita dificuldade na tarefa tradutória, e no caso de um texto shakespeariano categorizado como tragédia, não apenas envolve a questão cronológica que o separa de nossa contemporaneidade, como também a questão cultural e o dinamismo da língua, em que determinados vocábulos deixaram de ser usados, cabendo ao tradutor o papel de recriar e resgatar esses sentidos implícitos em sua língua.

Segundo Lucilia Teodora Villela de Leitgeb Lourenço e Tiago Marques Luiz, no que tange à tradução do humor para o palco, o cuidado é redobrado:

Se o texto dramático tem elementos cômicos, o que suscita problemas de tradução, é comum que este texto tenha dois destinos: ou ser eliminado ou ser substituído por um texto bem-humorado completamente diferente, desde que soe igualmente divertido na língua-alvo (LOURENÇO, LUIZ, 2018, p. 49).

Quando se pensa em traduzir Shakespeare, está se tratando do seu gosto pela ambiguidade, tanto a dramática quanto a linguística, pois no momento em que escrevia suas peças, o dramaturgo brincava com o sentido das palavras, uma vez que o trocadilho também "ajudava a deixar bem clara uma visão da vida que ele pretendia mostrar numa determinada peça" (MARTINS, 2004, p. 127), e como possivelmente trabalhava essas nuances com os atores no palco elisabetano. Para Shakespeare, o jogo de palavras, além de redimensionar o enredo da peça, também tinha como propósito agradar ao público frequentador do teatro, provenientes das variadas classes sociais. Por ser um texto escrito, os componentes semióticos podem vir registrados nas didascálias, de modo que possam permitir o leitor visualizar a encenação de determinada cena do texto e seu desenvolvimento. E mais precisamente no tocante à linguagem humorística, cabe ao ator transferir esse humor verbal no espaço do palco e ser convincente para o seu público, pois é papel do ator fazer com que o texto soe engraçado, segundo Marlene Fortuna (2000):

\footnotetext{
${ }^{86}$ No original: "On the one hand, any translation failure will therefore be very visible: it is obvious that the translator has filed when no one laughs at translated humor. On the other hand, the translator of humor has to cope with the fact that the "rules", "expectations", "solutions" and agreements on "social play" are often group -or culture-specific".
} 
rabalhado a partir do humor [...], o ator coloca-se disponível às mais diversas condições de liberdade na procura das possibilidades vocais. Passa a brincar com a técnica, não se permitindo mais ser escravizado por ela. [...] Tal liberdade se estende às extensões do seu ser, o ator dispõe-se a uma posição de completa interação com os circunstantes (FORTUNA, 2000, p. 85)

Ainda na esteira da problemática da tradução do humor, mais precisamente o trocadilho shakespeariano, cabe notar que este recurso, devido às mudanças da língua na perspectiva diacrônica, complicou o trabalho da exegese do legado do dramaturgo, seja por falta de documentos acerca dos trocadilhos usados na era elisabetana, seja porque novas ambiguidades surgiram (MARTINS, 2004, p. 127-128). Se os trocadilhos caracterizavam um desafio na própria língua inglesa, o mesmo pode ser dito em transpor o significado ambíguo no texto-alvo, devido ao caráter diacrônico da língua, problematizando a questão da equivalência, comprometendo - em certa medida - o estilo engenhoso e agudo que existe no humor shakespeariano.

A tragédia shakespeariana é envolvente, enquanto a comédia shakespeariana é transcendente, mas esses gêneros dramáticos são diferentes entre si. Como bem pontua Northrop Frye diz, a comédia amiúde "estabelece uma lei arbitrária e então organiza a ação para violá-la ou escapar dela, assim a tragédia apresenta o tema inverso de restringir uma vida comparativamente livre, num processo causal" (FRYE, 1973, p. 206). Dramaticamente, a cena em questão se opõe ao humor equívoco do sapateiro, com a volubilidade da multidão, denunciada nos tons de Marulo.

Se o espectador do período de Shakespeare considerava o sapateiro engraçado, ou aproveitando a licenciosidade do festival da Lupercália - portanto, uma festividade carnavalesca -, tais sentimentos são subjugados pelas palavras repreensivas de Marulo. Os plebeus não se lembram de que o festival remonta aos fundadores da cidade; portanto, os princípios de sua estrutura de governo e a ideia de quem os conduzirá estão em questão aqui. Esse tema do poder e seus limites é uma parte importante da peça.

A cena provoca algumas questões interessantes: a primeira é referente ao trocadilho filosófico do sapateiro, e a segunda diz respeito à identidade aparentemente ambígua do próprio personagem, ou seja, à própria incapacidade de Flavio o reconhecer como sapateiro, por estar usando suas melhores roupas, e porque o sapateiro se equivoca sobre sua identidade. 0 humor demanda um conhecimento implícito do tradutor e espectador, ou seja, uma competência cognitiva significativa para reconhecer os elementos do humor, além, é claro, da comunhão de duas ou três pessoas imaginárias, 
como propõe Jacques Le Goff (2000): a causadora do riso, o alvo e o receptor da mensagem humorística, e a existência desta tríade é "uma prática social com seus próprios códigos, seus rituais, seus atores e seu palco" (LE GOFF, 2000, p. 14).

O Sapateiro se diverte com Flavio e Marulo ao se valer de trocadilho correspondente ao universo da sapataria, usando palavras como "sole" como uma homofonia a "soul". 0 intuito do sapateiro para com os demais plebeus é fazê-los desgastarem suas sandálias, pois assim ele terá muito trabalho, entretanto, os tribunos mal-humorados acabam rapidamente com isso. A linguagem do sapateiro é considerada inapropriada quando dirigida a um oficial, o que faz dele um representante do desdém da classe trabalhadora perante o sistema político da época.

O sapateiro pede ao tribuno que não fique zangado com ele, mas caso estiver com raiva, ele poderia consertá-lo, e dizer isso, seria perigoso, vindo de um homem proveniente da classe operária. Sarcasticamente, o sapateiro está dizendo que, se o tribuno tiver uma alma ruim - ou seja, contra César, ele a consertaria.

Finalmente, o tribuno entende qual é o ofício do homem. Ele pergunta ao sapateiro: "0 que você quer dizer com me consertar?". 0 sapateiro descreve-se como um cirurgião de sapatos. Quando os sapatos estão em perigo, ele os recupera. Shakespeare ainda está aqui usando a ambiguidade em recuperar - tanto a sola do sapato, como a alma de alguém. Porém, para acabar com a algazarra, Flávio e Marulo interrompem a gritaria e ordenam que eles voltem ao trabalho. E é justamente nesse momento que o Sapateiro aparece, para justificar que é um dia de glória para todos na cidade. Flávio quer saber qual o ofício que aquele cidadão exerce, e é neste momento que inicia uma série de trocadilhos, pois o Sapateiro está ridicularizando os dois nobres por meio de jogos de palavras correspondente ao seu oficio.

O sapateiro acrescenta que muitos homens tiveram os calçados confeccionados pelas suas mãos. Esta é uma observação irônica referindo-se aos soldados e governo que não têm respeito pelo homem comum e seu árduo trabalho. Nesse momento, o sapateiro brinca dizendo que quer que os homens andem em seus sapatos, para que ele tenha mais trabalho com seus sapatos gastos. Na verdade, os plebeus estão ansiosos para ver César e celebrar suas vitórias.

As traduções consultadas para o presente trabalho comparativo foram de Carlos Alberto Nunes (1958), publicada pela Editora Melhoramentos, a de Carlos Lacerda 
(1965), publicada pela Record, a tradução de Bárbara Heliodora (2016), publicada e compilada pela Nova Aguilar, e a de José Francisco Botelho (2018), publicada pela Companhia das Letras, enquanto a edição usada como texto-fonte é a da Oxford Shakespeare (2005). Além desses cinco textos, foram consultadas edições anotadas e comentadas da referida peça, que pudessem nortear o nosso trabalho de tradução, assim como a elaboração das notas de rodapé. A partir desse cotejo e leitura das edições e traduções publicadas da peça, propõe-se aqui uma tradução anotada e comentada dessa cena.

\begin{tabular}{|c|c|}
\hline SHAKESPEARE $(2005$, p. 627$)$ & SHAKESPEARE (Tradução nossa) \\
\hline Act I, Scene I & Ato I, Cena I \\
\hline $\begin{array}{l}\text { Rome. A street. Enter Flavius, Marullus } \\
\text { and certain Commoners. }\end{array}$ & Uma rua de Roma. Entram Flávio, Marulo e alguns cidadãos. \\
\hline FLAVIUS: & FLÁVIO: \\
\hline Hence, home, you idle creatures get you & Para casa, seus vagabundos! Vão para casa! \\
\hline home! & Pensam que hoje é feriado? \\
\hline Is this a holiday? & Ou ignoram o fato de que \\
\hline What, know you not, & Por serem trabalhadores \\
\hline Being mechanical, you ought not walk & Não podem andar por aí em dias úteis \\
\hline Upon a labouring day without the sign & Sem o uniforme do seu ofício? \\
\hline $\begin{array}{l}\text { Of your profession? Speak, what trade art } \\
\text { thou? }\end{array}$ & Você aí! Diga, qual sua profissão? \\
\hline CARPENTER: & CARPINTEIRO \\
\hline Why, sir, a carpenter. & Ora, meu bom senhor, sou carpinteiro. \\
\hline MARULLUS: & MARULO \\
\hline Where is thy leather apron and thy rule? & Cadê o avental de couro e a régua? \\
\hline What dost thou with thy best apparel on? & E esses trajes ultrajantes ${ }^{87} ?$ \\
\hline You, sir, what trade are you? & E você, rapaz, trabalha com o que? \\
\hline COBBLER: & SAPATEIRO \\
\hline $\begin{array}{l}\text { Truly, sir, in respect of a fine workman, I } \\
\text { am but, as you would say, a cobbler. }\end{array}$ & $\begin{array}{l}\text { Ora, meu senhor, comparado a um obreiro de primeira } \\
\text { linha }{ }^{88} \text {, sou o que se considera, vamos dizer, um remendão. }\end{array}$ \\
\hline MARULLUS: & MARULO \\
\hline $\begin{array}{l}\text { But what trade art thou? Answer me } \\
\text { directly. }\end{array}$ & Remendão de que? Anda ${ }^{89}$, responda, sem rodeios! \\
\hline COBBLER: & SAPATEIRO \\
\hline
\end{tabular}

\footnotetext{
${ }^{87}$ A expressão "traje ultrajante", além do jogo de palavras para com a palavra "traje", é para fazer menção a uma roupa de boa qualidade, usada em alguma ocasião - como ir à missa, por exemplo.

${ }^{88}$ A expressão "trabalhador de primeira linha", propõe uma ambiguidade: primeira linha como sentido de prestigio, como também de linha de costura, pela qual o sapateiro remenda os calçados.

${ }^{89}$ Primeiro indício de Marulo estar perdendo a paciência ao usar o imperativo "anda". Essa marca imperativa é comum quando alguém perde a paciência ou quer algo esclarecido.
} 
A trade, sir, that, I hope I may use with a safe conscience, which is, indeed, sir, a mender of bad soles.

\section{FLAVIUS:}

What trade, thou knave? Thou naughty knave, what trade?

\section{COBBLER:}

Nay, I beseech you, sir, be not out with me. Yet, if you be out, sir, I can mend you.

\section{MARULLUS:}

What mean'st thou by that? Mend me, thou saucy fellow?

\section{COBBLER:}

Why, sir, cobble you.

\section{FLAVIUS:}

Thou art a cobbler, art thou?

\section{COBBLER:}

Truly, sir, all that I live by is with the awl. I meddle with no tradesman's matters, nor women's matters, but withal I am indeed, sir, a surgeon to old shoes: when they are in great danger, I recover them. As proper men as ever trod upon neat's leather have gone upon my handiwork.

Flavius:

But wherefore art not in thy shop today? Why dost thou lead these men about the streets?

\section{COBBLER}

Truly, sir, to wear out their shoes, to get myself into more work.

But indeed, sir, we make holiday to see Caesar, and to rejoice in his triumph.

\section{Marullus}

Wherefore rejoice? What conquest brings he home?
Meu senhor, uma profissão ofício que pratico de consciência tranquila. Eu costuro as furadas ${ }^{90}$.

\section{FLÁVIO}

Que furada, seu descarado? Seu cara de pau, qual é o seu trabalho?

\section{SAPATEIRO}

Meu senhor, eu lhe peço, não se desgaste. Se se desgastar ${ }^{91}$, no gasto eu dou um trato ${ }^{92}$.

\section{MARULO}

Como assim, me dar um trato, seu safado?

\section{SAPATEIRO}

Ora, senhor, costurar seus furos.

\section{FLÁVIO}

Então o senhor é sapateiro?

\section{SAPATEIRO}

Sim, senhor, costurando a vida pela costura da sovela ${ }^{93}$. Não meto em negócios ou em coisas de mulheres ${ }^{94}$, senão pela sovela ${ }^{95}$; mas, meu senhor, eu salvo sapatos que não tem salvação; quando ameaçados, eu os resgato. Muitos homens calçaram o couro tratado e trabalhado por essas mãos ${ }^{96}$.

\section{FLÁVIO}

E por que não está na sua loja?

Por que anda com esses homens pela rua?

\section{SAPATEIRO}

Ora, para gastarem as solas que me farão trabalhar. Mas, senhor, cá entre nós, para ser franco, nós nos demos uma folga para encontrar César e festejar seu triunfo.

\section{MARULO}

Festejar o quê? Quais foram as conquistas? Que vassalos são esses que o seguem rumo à Roma,

\footnotetext{
90 Trocadilho: Furada como sinônimo de erros dos outros, como também o furo dos sapatos. Pensar no furo enquanto um erro da alma, faz com que o público reflita sobre o seu destino, uma vez que a piedade e o medo são elementos trágicos.

91 Trocadilho, onde desgastar tem sentido ambíguo: desgaste de sola do sapato, como também desgaste emocional (raiva). Sugestão também de jogo de palavra com gasto e trato.

92 Trocadilho: A gíria 'dar um trato' significa melhorar, geralmente usado na questão da aparência: dar um trato no visual. No caso dessa cena, o Sapateiro usa o duplo sentido para fazer menção tanto ao descontento de Marulo como no sapato.

93 A sovela é uma ferramenta usada na sapataria, como uma espécie de agulha, usada para fazer furos no couro, e nesses furos, passa-se uma linha para a costura adentrada.

${ }^{94}$ Ele não se mete em assuntos de mulher, a não ser pela sovela, ou seja, senão pelo ato sexual.

95 De modo figurado, seu pênis.

${ }^{96}$ Couro trabalhado por essas mãos - As mulheres com quem o sapateiro se relacionou.
} 
What tributaries follow him to Rome,

To grace in captive bonds his chariot wheels?

You blocks, you stones, you worse than senseless things!

0 you hard hearts, you cruel men of Rome, Knew you not Pompey? Many a time and oft

Have you climb'd up to walls and battlements,

To towers and windows, yea, to chimneytops,

Your infants in your arms, and there have sat

The livelong day, with patient expectation,

To see great Pompey pass the streets of Rome:

And when you saw his chariot but appear, Have you not made an universal shout, That Tiber trembled underneath her banks

To hear the replication of your sounds Made in her concave shores?

And do you now put on your best attire? And do you now cull out a holiday?

And do you now strew flowers in his way, That comes in triumph over Pompey's blood? Be gone!

Run to your houses, fall upon your knees, Pray to the gods to intermit the plague That needs must light on this ingratitude.

\section{Flavius}

Go, go, good countrymen, and for this fault Assemble all the poor men of your sort; Draw them to Tiber banks, and weep your tears

Into the channel, till the lowest stream Do kiss the most exalted shores of all.

\section{[Exeunt all the Commoners]}

See where their basest mettle be not mov'd;

They vanish tongue-tied in their guiltiness.

Go you down that way towards the Capitol;

This way will I. Disrobe the images,

If you do find them deck'd with ceremonies.
Acorrentados como escravos nas rodas de sua carruagem? Seus cabeças-duras, seus insensíveis e estapafúrdios. Vocês são piores que os materiais insensíveis.

Oh, corações desalmados, homens desumanos de Roma! Não conheceram Pompeu ${ }^{97}$ ? Incontáveis vezes

Vocês escalaram muros e ameias,

Torres e janelas, sim,

Até mesmo as chaminés ${ }^{98}$,

Com seus filhos em seus braços, e assim se sentaram,

0 dia inteiro, esperando pacientemente por Pompeu, o

Grande

Que ele passasse e os avistasse pelas ruas de Roma.

E quando viam a carruagem surgir

Não gritaram em bom e alto som

A ponto do Tibre ${ }^{99}$ abalar suas margens

Ao ouvir ecos de seus gritos

Entre suas costas curvas?

E agora vocês vestem as melhores roupas?

Plantam semana pra colher feriado ${ }^{100}$ ?

E agora jogam tapetes de flores para a via sacra,

Daquele que triunfou sobre os filhos de Pompeu ${ }^{101}$ ?

Sumam daqui!

Voltem para suas casas e ajoelhem, clamando

Aos deuses que sustem a peste

Que cairá sobre vocês por desmedida ingratidão!

\section{Flávio}

Vão, vão, amados compatriotas, e para expurgar esse mal Reúnam aqueles que são pobres como vocês

E levem eles ao canal do Tibre para lacrimejar Até que essas águas, mesmo na mais baixa corrente, Possam beijar as mais sublimadas de todas as costas

Saem todos os Cidadãos.

Isso deve fazer com que aqueles mais temperamentais Se sintam presos em sua própria língua, plenos de remorsos.

Agora, vá por ali, rumo ao Capitólio

E eu vou por aqui. Desvista as estátuas

Caso estejam adornadas de enfeites.

\footnotetext{
97 Pompeu foi aliado e genro de Júlio Cesar, tendo se casado com sua filha, Júlia.

98 Torres, Janelas e Chaminés - uma possível referência para a Londres de Shakespeare.

${ }^{99}$ Rio da costa italiana

${ }^{100}$ Aqui é uma ironia de Marulo, porque os operários não tinham oportunidade de escolher seus feriados.

101 Sangue de Pompeu e seu exército.
} 


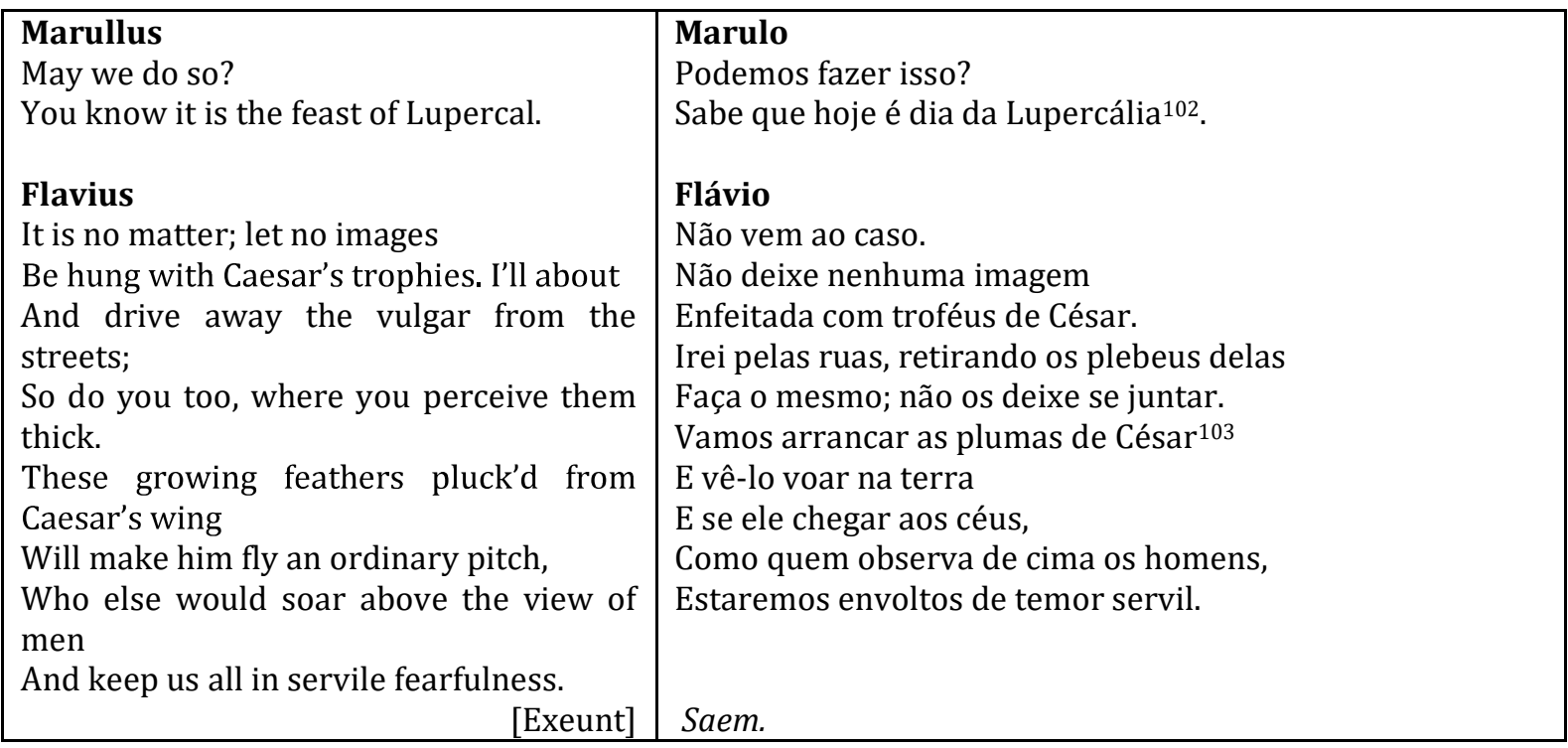

A tradução proposta teve como intuito resgatar a comicidade, como também ressaltar o uso e abuso de Shakespeare em relação ao trocadilho. Nessa cena especificamente, o Sapateiro, enquanto um personagem pertencente às classes mais baixas, mais precisamente a classe operária, mostra realmente o tipo de discurso que essa classe demonstra em relação aos seus superiores. Ele não mostra nenhum tipo de respeito para com os tribunos Flávio e Marulo, a ponto de humilhá-los, ridicularizando-os por meio de palavras correspondentes ao universo da sapataria, como remendar, costurar, furos e sovela.

Quando se cotejou as traduções de Carlos Alberto Nunes, Carlos Lacerda, José Botelho e Bárbara Heliodora, foi possível constatar que cada tradutor optou por uma escolha lexical no momento de fazer a sua tradução. Carlos Alberto Nunes é muito conhecido por traduções muito rebuscadas, e apesar de muitas palavras estarem em desuso em nossa contemporaneidade, o mérito desse tradutor está no empenho de traduzir todas as peças do Shakespeare para a língua portuguesa. A respeito do trocadilho, manteve-se o universo referente ao campo da sapataria, enfocando apenas o uso de segunda pessoa do singular.

\footnotetext{
1020 radical luper (Lobo) remete à loba que amamentou Romulo e Remo. Era uma festança que tinha como intento afugentar os maus espíritos e a purificação da cidade. Marcada pela licenciosidade, foi um modelo adotado posteriormente no carnaval. Essa festa teve tradição forte no tempo de Júlio Cesar.

${ }^{103}$ Metáfora para se referir ao apoio da classe operária. Também é uma metáfora para destituir a grandeza de César. A imagem da pluma vem da falcoaria, sendo César o falcão, cuja "asa" (poder) será mais fraca se suas penas (o apoio popular) forem arrancadas, fazendo com que voe em um "tom" mais baixo (altura).
} 
Sobre Carlos Lacerda, temos conhecimento de que a sua tradução de Júlio César foi publicada no período da ditadura da Era Vargas, portanto, contendo um certo teor político e ideológico vigente naquela época:

[...] o que tinha acontecido no Brasil era o que aconteceu no drama de Shakespeare, e não foi à toa que traduzi esse drama: Júlio César. A mesma multidão que aclamava Brutus e os que mataram César, quando Marco Antônio fez seu discurso com o cadáver nos braços, começou a pedir a morte dos que tinham assassinado César. [...] Foi assim que passei de vítima a assassino de Vargas. [...] Vargas, que num certo momento era, não digo odiado, mas desprezado pela maioria do povo, ao morrer, ou por sentimentalismo, ou por causa desse tipo de exploração, ou ainda por um natural pudor nosso de não continuar a atacar um homem que tinha se suicidado [...] passou a ser o Júlio César de Shakespeare (LACERDA, 1978, p. 147-149).

A tradução de Júlio César feita por Lacerda foi publicada em 1965. Segundo Eliane Euzébio (2007), a primeira impressão que causou na época é de que a tradução da referida peça shakespeariana tinha como intuito de fazer a nação brasileira pensar, como forma de espelhar o golpe de 1964, no qual João Goulart foi deposto da Presidência, fazendo alusão à maneira como Júlio César foi deposto brutalmente por Brutus. A tradução dos trocadilhos também soube respeitar a ambiguidade nas falas do Sapateiro, e ao contrário de Nunes, a sua tradução optou por empregar a terceira pessoa do singular.

A tradução de José Botelho, publicada em 2018, já é mais contemporânea, contudo, cabe ressaltar que a peça Júlio César tem um caráter político implícito na sua própria narrativa, como a própria questão do assassinato do imperador e um complô contra o mesmo. Sobre a tradução de Bárbara Heliodora, nota-se que a tradutora e especialista em Shakespeare teve a preocupação em manter mesma quantidade de linhas e versos semelhante ao original. Os dois tradutores também souberam lidar com a exegese da semântica proposta no trocadilho, apenas diferenciando-se no emprego de segunda (Botelho) e terceira (Heliodora) pessoa do singular.

A tradução dessa cena nos chamou a atenção, por ser a primeira cena que abre a peça marcada de comicidade no diálogo entre os personagens, assim como vemos essa mesma particularidade na cena de abertura em Romeu e Julieta, com Sansão e Gregório. A tradução aqui proposta está destinada não somente a leitura, mas também à sua encenação, para que o ator, no momento da encenação e durante os ensaios, seja capaz de convencer o seu espectador da particularidade que é o sapateiro: um personagem de origem simples, marcado pelo constante uso de linguagem humorística. Outrossim, nossa 
tradução vai ao encontro da proposta de Bárbara Heliodora, de que cabe ao tradutor e ao ator, quando trabalharem o texto, encontrar "a forma adequada de expressar seu significado - para o bem do público, que assim recebe a devida orientação tanto para o conteúdo quanto para a beleza de qualquer peça” (HELIODORA, 2018, p. 178).

No tocante ao público, pensamos em um público acadêmico proveniente das Letras e das Artes Cênicas, dada a articulação entre esses campos do saber para com o texto shakespeariano, e que no caso de uma eventual encenação por uma companhia teatral, no tocante à essa cena cômica, é preciso que haja preocupação sobre como o significado é transmitido na performance. Mais precisamente com cenas trocadilhescas, a encenação tem que preservar o conteúdo presente no texto-fonte, não apenas para evitar incongruência ou incompreensão por parte da plateia, mas para que ambos "forma e conteúdo coexistiam da maneira mais exemplar" (HELIODORA, 2018, p. 178).

No tocante à potencialização do texto escrito para o palco, é necessário pontuar que há "dois aspectos específicos que apresentam maior dificuldade são: a) a concisão da forma dramática, e b) a necessidade de entendimento imediato por parte da plateia" (HELIODORA, 2018, p. 182), e em uma relação de causa e consequência durante os ensaios, é o texto que norteia o trabalho do ator [causa] e é a sua interpretação corporal, oral e criatividade que irão desencadear o riso na plateia [consequência]

Fazendo uma articulação entre tradução e teatro, citamos Adam Versényi (2015), que dirá que tradução não é apenas língua assim como o teatro não é só texto; para ele, ambos "tradução e teatro também são, fundamentalmente, sobre como experimentamos e pensamos sobre nós mesmos" (VERSÉNYI, 2015, p. 289, tradução nossa104).

A tradução trouxe uma escolha lexical mais contemporânea possível, justamente tendo como intuito de servir como um roteiro para o ator no palco, empregando a terceira pessoa do singular, de forma que esse diálogo entre os personagens seja sutil e inteligente, cabendo lembrar que a tradução para o palco vai se potencializar justamente no momento em que o ator externaliza o material escrito. Logo, houve uma preocupação em se lidar com a própria dicção do personagem, a sua caracterização e, por conseguinte, a própria linguagem gestual, pois no momento em que o sapateiro fala, por exemplo, da questão da sovela, ele faz alusão ao pênis. 104 No original: "both translation and theatre are also, fundamentally, about how we experience and think
about ourselves". 
Então decidiu-se, ao cotejar as traduções e consultando as edições anotadas e comentadas da peça, transpor um texto com diálogo inteligente e sutil, mas que ressaltasse o trocadilho, esse dispositivo retórico do qual Shakespeare é bastante reconhecido na composição das suas peças. Espera-se que essa tradução seja trabalhada com alunos de teatro, os quais, amparados pela linguagem cênica, possam ressignificar o conteúdo que está ali inscrito. 0 texto dá as nuances, mas é justamente no momento da interação no palco é que o sentido do texto se torna perceptível.

A respeito da linguagem humorística dentro dessa cena, houve a preocupação em trazer o sentido duplo do diálogo, porque o Sapateiro está toda hora fazendo piada com os tribunos, pois o clown, personagem que esse do qual o sapateiro faz jus, é justamente o personagem marcado pela própria inteligência e esperteza em confrontar o seu superior, como é o caso da homofonia entre soul e sole para tratar tanto do ofício do personagem como do estado de espírito dos homens.

Pode-se até fazer um paralelo com o coveiro de Hamlet, o que seria um trabalho posterior, mas que fica como possível sugestão para o pesquisador que quiser cotejar esses personagens, por meio de um trabalho comparativo. Espera-se que essa tradução possa soar risível tanto na leitura como na encenação, e também legível, no que diz respeito às escolhas lexicais.

0 primeiro termo em inglês, "idle", significa uma pessoa inútil, preguiçosa indolente, vagabunda, e os tradutores optaram por "vagabundos", por ser algo mais direto, ao invés de "ocioso", por exemplo. 0 próximo termo em língua inglesa, "sign of profession", significa um símbolo que ressaltasse a profissão, entretanto, optou-se por traduzir como "uniforme", por ser mais condizente ao trabalhador, que traja uma roupa condizente com o local de trabalho.

Flávio usa o termo "trade", que significa profissão, ofício, optando por utilizar os dois termos, de modo que não ficasse repetitivo. Marulo questiona ao Sapateiro sobre o "best apparel", termo que significa a melhor roupa, que corresponderia ao "traje domingueiro", mas pensando na paronomásia, optou-se por "trajes ultrajantes", propondo o jogo linguístico com a palavra traje.

o Sapateiro traz o lexema "fine workman", que significa exatamente os trabalhadores de maior prestígio, foi traduzido como "trabalhador de primeira linha", gerando ambiguidade: primeira linha como sentido de prestígio, um trabalhador 
renomado, como também de linha de costura, pela qual o sapateiro remenda os calçados. No próximo diálogo, vemos o sapateiro falar que é um "mender of bad soles", que em língua inglesa já proponha trocadilho homófono entre "soul" e "sole". Pensando justamente nessa ideia de fazer um trocadilho com as palavras, optamos por traduzir esse fragmento como "remendão das furadas dos outros", em que furada vai compreender tanto o furo do calçado como o erro dos outros.

Sem entender ainda qual que é a verdadeira profissão do personagem, Flávio fica indignado e enraivecido e pede que ele diga qual que é a sua profissão sem muitos rodeios, ou seja, sem utilizar muitos artifícios para dizer o que ele realmente é. 0 sapateiro pede para que o tribuno não fique zangado, como propõe o termo em língua inglesa "be out". Justamente pensando esse trocadilho em que propõe "be out", optou-se por utilizar o verbo desgastar, que remete não só desgastar no sentido emocional, de esbravejar raiva e ira, mas também desgastar as suas solas dos sapatos. E quando o sapateiro utilizou verbo "to mend", ele quis dizer que, ele podia corrigir, costurar e remendar, significando então que ele quer corrigir não somente a sola do sapato, mas também acalmar os ânimos do tribuno, de forma ridicularizada por meio da gíria "dar um trato".

Quando Flávio compreende que o cidadão em questão é um sapateiro, o cidadão responde de prontidão, dizendo que ganha a vida pela sua sovela, ou seja, que não subsiste apenas pelo seu trabalho manual, mas também pelas próprias relações sexuais, uma vez que a sovela tem uma estrutura semelhante ao pênis. A solução encontrada foi propor um jogo de palavras com o verbo costurar, que remete tanto ao ato da costura de um calçado, como também uma sugestão de ganhar a vida, como remendar de alguma forma a subsistência. Portanto, quando ele fala que não se mete em negócios e nem em coisa de mulheres a não ser pela sovela, significa que nada passa por ele a não ser por uma relação sexual. 0 termo em língua inglesa "women matters" pode significar "assunto de mulheres", mas optou-se por traduzir como "coisas de mulher", justamente para ficar implícito de que a coisa de mulher não necessariamente seria um assunto condizente ao respeito ao universo feminino, mas ao aparelho reprodutivo feminino.

Em seguida, ele fala que é um cirurgião de velhos sapatos, valendo-se de certa carga filosófica, pois quando utiliza um discurso um pouco erudito, está dizendo que enquanto o mundo está em perigo, ou seja, os sapatos no caso, ele os recupera. E ao mencionar homens refinados andaram sobre couro de boi, esse couro não vai significar o material 
utilizado na confecção de calçado, mas uma metáfora para relacionar ao corpo feminino; o sapateiro teve relações sexuais com as mulheres dos homens que foram para a guerra, ou seja, dizer que esse couro foi trabalhado sobre suas mãos, significa que teve relações sexuais com mulheres da nobreza.

Por fim, quando Flávio pergunta porque que ele está andando com esses homens pela rua, o Sapateiro imediatamente responde de prontidão que é para justamente ter trabalho, ou seja, espera que esses homens desgastem os seus calçados; quanto maior o desgaste do calçado, maior o retorno financeiro desse trabalho. Fora essa questão pragmática, ele justifica que todos têm interesse de comemorar a vitória de César, tornando aquele dia um dia de folga, pelo fato de que César venceu uma batalha contra os filhos de Pompeu.

Não muito satisfeito com a resposta, Marulo já esbraveja, questionando quais conquistas que César trouxe para Roma, como também afirma que os plebeus não tem conhecimento de quem foi Pompeu, e que por conta disso, seriam ingratos, desprovidos de raciocínio, e também vagabundos perambulando pelas ruas, gritando o nome de César como se fosse o Salvador da Pátria, quando na verdade Marulo está condenando essa conduta dos plebeus.

Flávio acaba acalmando os ânimos do amigo e diz que os homens podem sair para comemorar a vitória de César, contudo no momento em que os plebeus saem das ruas, Flávio já agiliza um plano com Marulo de destruir ou simplesmente desvestir as estátuas de César, que estavam ornamentadas com enfeites, como por exemplo, coroas de oliveira. Esse diálogo entre Flávio e Marulo no final da cena é nada mais nada menos um planejamento dos tribunos para castigar aqueles que são a favor de César e contra Brutus, até porque o Sapateiro deixa claro que os tribunos não são a favor de César como guerreiro e como governador.

\section{Considerações finais}

Cabe ressaltar aqui que essa tradução não é definitiva, pois temos ciência de que as peças do bardo estão sempre sujeitas à novas roupagens e interpretações, como também de escolhas lexicais. E propor uma tradução está além do conhecimento linguístico do texto-fonte e do texto traduzido; é uma atividade que demanda uma gama 
de leituras acerca do estilo de determinado autor, a sua época e consequentemente o seu texto, de modo que o texto-traduzido possa resgatar as particularidades do texto original, pois o tradutor tem uma tarefa que consiste em encontrar na língua-alvo "a intenção, a partir da qual o eco do original é nela despertado. [...] a intenção do escritor é ingênua, primeira, intuitiva; a do tradutor, derivada, última, ideativa" (BENJAMIN, 2010, p. 217).

Tal como um dramaturgo escreve a sua peça, o tradutor também tem que ter essa aptidão de ler o texto em voz alta, de modo que o conteúdo escrito seja convincente, para pensar a sua verbalização na boca do ator. Ao contrário do diálogo literário, o diálogo teatral difere-se por ser enunciado em voz alta, necessitando do corpo e da voz do ator. Pode-se concluir que o tradutor, enquanto estiver situado no entremeio entre duas culturas e dois textos, mediará o processo de fazer com que a língua-fonte seja traduzida e adaptada ao seu público-alvo, tanto nos aspectos semânticos e sintáticos, e porque não acústicos do texto-fonte, tendo em mente que o texto verbalizado pelo ator será recebido pelo público, e é justamente esse público que dará a resposta ao ator e tradutor, isto é, se ambos chegaram ao seu objetivo (no caso dessa cena, fazer rir), e se as escolhas lexicais foram um acerto.

Na reflexão de Delabastita (1996), pontuar uma resposta definitiva para a tradução e como traduzir o humor shakespeariano é de caráter tendencioso, uma vez que essa resposta está intrínseca ao tipo de tradução que se tem mente, ou seja, no tocante ao grau da equivalência como também nos gêneros tradutórios, como também enquanto interlocutor “em relação ao negócio real da tradução (se alguém está falando como professor de tradução, como praticante, crítico, teórico, historiador, filósofo da linguagem)" (DELABASTITA, 1996, p. 127, tradução nossa105).

Por fim, mas não menos importante, o tradutor teatral de conteúdos cômicos está inserido em um contexto cultural totalmente diverso daquele que produziu o texto de partida, e há de ter ciência de que determinado conteúdo nem sempre surtirá o mesmo efeito no seu público pretendido, tal como ocorreu no texto de partida, e caberá a ele recriar o conteúdo desejado na sua língua, sem também se distanciar da fluidez da narrativa.

\footnotetext{
105 No original: vis-a-vis the actual business of translation (whether one is speaking as a teacher of translation, as a practitioner, a critic, a theorist, a historian, a philosopher of language).
} 


\section{REFERÊNCIAS}

ATTARDO, S.. Translation and Humour: An Approach Based on the General Theory of Verbal Humour (GTVH). In: VANDAELE, J. (ed.) The Translator. Volume 8, Number 2. Special Issue. Translating Humour. Manchester: St. Jerome Publishing, 2002, p. 173194.

BASSNETT, S. Reflections on Translation. Series Topics in Translation. Bristol, Buffalo, Toronto: Multilingual Matters, 2011.

BENJAMIN, W.. A Tarefa do Tradutor. Tradução de Susana Kampff Lages. In: HEIDERMAN, W. (org). Antologia Bilíngue "Clássicos da Teoria da Tradução". 2ª ed., revisada e ampliada. Volume I: Alemão-Português. Florianópolis: UFSC/NUPLITT, 2010, p. 202-231.

BLOOM, H. Shakespeare: a invenção do humano. Tradução de José Roberto O’Shea. Rio de Janeiro: Objetiva, 2001.

CHIARO, D.. Translation. In: ATTARDO, S. (ed). Encyclopedia of Humor Studies. Volume 1. USA: Sage Reference, 2014, p. 1394-1398.

DELABASTITA, D. Introduction. The Translator, Manchester, vol. 2, núm. 2, p. 127-139, 1996.

A Great Feast of Languages: Shakespeare's Multilingual Comedy in 'King Henry V' and the Translator. The Translator, Manchester, vol. 8, núm. 2, p. 303-340, 2002.

EUZÉBIO, E.. O Poder das Idéias: As Traduções com Objetivos Políticos de Carlos Lacerda. 2007. 125f. Dissertação (Mestrado em Estudos Lingüísticos e Literários em Inglês) - Faculdade de Filosofia, Letras e Ciências Humanas, Universidade de São Paulo, São Paulo, 2007.

FORTUNA, Marlene. A performance da oralidade teatral. 1a edição. São Paulo: Annablume, 2000.

FRYE, N.. Anatomia da Crítica. Tradução de Péricles Eugênio da Silva Ramos. São Paulo: Editora Cultrix, 1973.

HELIODORA, B.. Meus motivos para traduzir Shakespeare/ My reasons for translating Shakespeare. Tradução de Thelma Christina Ribeiro Côrtes. In: MARTINS, M. A. P.; GUERINI, A. (orgs). Palavra de Tradutor: Reflexões sobre tradução por tradutores brasileiros/ The Translator's Word: Reflections on Translation by Brazilian Translators. Edição bilíngue. Florianópolis: Editora da UFSC, 2018, p. 177193.

HURTADO ALBIR, A. Traducción y. Traductología. Introducción a la Traductología. Madrid: Cátedra, 2001. 
JAKOBSON, R.. Lingüística e Comunicação. 24 ed. Prefácio de Izidoro Blikstein. Tradução de Izidoro Blikstein e José Paulo Paes. São Paulo: Cultrix, 2007.

LACERDA, C.. Depoimento. Rio de Janeiro: Editora Nova Fronteira, 1978.

LE GOFF, J.. 0 riso na Idade Média. In: BREMMER, J.; ROODENBURG, H. (orgs.). Uma história cultural do humor. Tradução de Cynthia Azevedo e Paulo Soares. Rio de Janeiro: Record, 2000, p. 65-82.

LEIBOLD, A.. The Translation of Humor: Who Says It Can't Be Done?.Meta, Montréal, vol. 34, n. 1, March, p. 109-111, 1989.

LOURENÇO, L. T. V. L.; LUIZ, T. M.. O humor do sapateiro da peça Júlio César em tradução comparada. In: SILVA, S. C.; LUIZ, T. M. (orgs). 0 Humor nas Literaturas de Expressão de Língua Inglesa. Jundiaí: Paco Editorial, 2018, p. 39-63.

MARTINS, M. A. P.. Traduzindo o trocadilho: o humor de $O$ mercador de Veneza em português. In: MARTINS, M. A. P. (org). Visões e identidades brasileiras de Shakespeare. Rio de Janeiro: Lucerna, 2004, p. 127-148.

MINOIS, G. História do riso e do escárnio. Tradução de Maria Elena Ortega Ortiz Assumpção. São Paulo: Editora da UNESP, 2003.

NASON, A. H. Shakespeare's use of comedy in tragedy. The Sewanee Review, v. 14, n. 1, 1906, p. 28-37.

A tradução dos jogos de palavras shakespearianos: o caso de $\boldsymbol{A}$ Megera Domada. In: CAMATI, A. S.; MIRANDA, C. A.. Shakespeare sob múltiplos olhares. $2^{\text {a }}$ edição. Curitiba: Editora da UFPR, 2016, p. 287-314.

SHAKESPEARE, W.. Julius Caesar. In: JOWETT, J.; MONTGOMERY, W.; TAYLOR, G.; WELLS, S.. (eds.). William Shakespeare - The Complete Works. The Oxford Shakespeare. $2^{\text {nd }}$ ed. United Kingdom: The Oxford University Press, 2005, p. 627-654.

. Júlio César e Antônio e Cleópatra. Tradução de Carlos Alberto Nunes. Coleção Obras Completas de Shakespeare. Volume IX: Tragédias. São Paulo: Editora Melhoramentos, 1958.

. Júlio César. Tradução de Carlos Lacerda. Coleção Trabalhos Literários de Carlos Lacerda. Rio de Janeiro: Record, 1965.

Júlio César. Tradução de Bárbara Heliodora. Coleção Teatro Completo - Volume 1: Tragédias. São Paulo: Nova Aguilar, 2016, p. 241-347.

. Júlio César. Tradução e notas de José Francisco Botelho. Prefácio de Harold Bloom. 1a ed. São Paulo: Penguin Classics Companhia das Letras, 2018. 
1985.

Julius Caesar. Edited by Hilda M. Hume. New Swan Shakespeare. UK: Longman,

Julius Caesar. Edited by John Dover Wilson. The Cambridge Dover Wilson Shakespeare. Volume 15. Cambridge: Cambridge University Press, 2009.

Julius Caesar. Translated by Mary Ellen Snodgrass. Collection Shakespeare on the Double!. New Jersey: Wiley Publishing House, 2006.

Julius Caesar. Edited by Sidney Lamb. Commentary by Diana Sweeney. Collection Cliffs Complete. New York: Hungry Minds, 2000.

Julius Caesar. Edited and rendered into modern English by Phyllis A. Corzine. Collection Simply Shakespeare. New York: Barrons, 2002.

VANDAELE, J.. Humor in Translation. In: GAMBIER, Y.; VAN-DOORSLAER, L. (eds). Handbook of Translation Studies. Volume 1. Amsterdam: John Benjamins Publishing Company, 2010, p. 147-152.

VERSÉNYI, A.. The dissemination of theatrical translation. In: ROMANSKA, M. (ed). The Routledge Companion to Dramaturgy. London and New York: Routledge, 2015, p. 288-293.

ZABALBEASCOA, P.. La traducción del humor en textos audiovisuales. In: DURO, M.. La traducción para el doblaje y la subtitulación. Colección signo e imagen, número 63. Madrid: Cátedra, 2001, p. 251-263.

Biografia dos autores

\section{Biografia dos autores}

Tiago Marques Luiz possui graduação em Letras Licenciatura/Habilitação Português/Inglês pela Universidade Federal da Grande Dourados (2009), especialização em Tradução de Inglês pela Universidade Gama Filho (2011), Mestrado em Estudos da Tradução pela Universidade Federal de Santa Catarina (2013) e Doutorado em Estudos Literários pela Universidade Federal de Uberlândia (2019). Atualmente é professor convocado na Universidade Estadual de Mato Grosso do Sul.

Lucilia Teodora Villela de Leitgeb Lourenço possui graduação em Ciências Jurídicas e Sociais pela Faculdade de Direito da Alta Paulista (1973) e graduação em Letras Português/Inglês pela Universidade de Marília (1972). É Mestra em Letras pela Universidade Federal de Mato Grosso do Sul (2006) e Doutora em Letras pela Universidade Federal do Rio Grande do Sul (2014). É professora efetiva nível V da Universidade Estadual de Mato Grosso do Sul, em Dourados. 